\section{P-186 WIRRAL END OF LIFE CARE CHARTER}

${ }^{1}$ Julie Gorry, ${ }^{2}$ Paul McGovern, ${ }^{2}$ Jane Fletcher, ${ }^{3}$ Clare Brown, ${ }^{4}$ Annette Thwaites, ${ }^{5}$ Kate Gratwick, 'Liz Rice, 'Judi Ebrell, ${ }^{1}$ Jo Coulson, ${ }^{6}$ Adrian Quinn. 'Wirral Hospice, Wirral, UK; ${ }^{2}$ Wirral CCG; ${ }^{3}$ Wirral University Teaching Hospital; ${ }^{4}$ Wirral Community Trust; ${ }^{5}$ Healthwatch Wirral; ${ }^{6}$ Wirral Social Services

\subsection{6/bmjspcare-2016-001245.208}

The concept for the creation of a Wirral end of life care charter was born from the necessity for the Wirral Palliative Care and End of Life Care Partnership Group to focus on the need to take stock of a whole range of policy and guideline directives to create and deliver services for patients, their families and carers during the difficult journey through the last year of life and up to the days and hours before death.

The challenge was how could we as health and social care providers, patient and carer representatives and commissioners focus on efforts to effectively deliver the levels of quality care and support, with the necessary skills and compassion in a coherent way, and importantly one which patients carers and families and the community of Wirral can relate to.

We decided what was needed was a set of pledges in the form of a charter that explains what patients and those close to them may expect from providers of care and support, and of equal importance what providers must do to resource and support staff to deliver first class quality care for palliative patients at the end of their lives.

The launch took place with a range of key speakers to both set the scene in terms of supporting Dying Matters Week and to inform as wide an audience as was possible of developments and challenges facing palliative and end of life care in the future. We are proud to say that all Wirral statutory deliverers of health and social care duly signed up and pledged support. "One year on" an endoflifecarewirral.org website has been launched.

\section{P-187 WORKING IN PARTNERSHIP ACROSS CHARITABLE AND STATUTORY SECTORS - MAKING A REAL DIFFERENCE TO CHILDREN AND THEIR FAMILIES}

${ }^{1}$ Jacqui Scrace, ${ }^{2}$ Ali Acaster, ${ }^{3}$ Liz Lewington, ${ }^{4}$ Jayne Abbott, ${ }^{5}$ Karen Glastonbury. ${ }^{1}$ Naomi House and Jacksplace, Winchester, Hampshire; ${ }^{2} J u l i a ' s ~ H o u s e ; ~{ }^{3}$ Jessie May Trust; ${ }^{4}$ Rainbow Trust; ${ }^{5}$ NHS, Salisbury Children's Community Nursing Team

\subsection{6/bmjspcare-2016-001245.209}

The challenge is for the hospice to set up a community service, across a number of different counties, to deliver regular respite as well as palliative and end of life care for children and their families.

The only way that this can be achieved is to work in partnership, both formally and informally, with other organisations. In order to introduce a new community service in Wiltshire, a formal partnership has been agreed between the hospice and another community hospice provider.

To ensure collaboration with existing service providers in the area, a 'Wiltshire Partnership group' has been formed, which includes representatives from the hospice and three other charitable organisations ( 2 of which are community hospice services) as well as one statutory service. Each service currently delivers slightly different support to children with life limiting and life threatening conditions. The benefits of working together are many, including; seamless delivery of care for children and families, improved communication between services, shared referrals across organisations, improved choice of care, reduce parental anxiety and increased access to support, as well as improved access to end of life care at home with all organisations contributing to a shared rota to cover 24/7. A model highlighted in a recent report titled; NHS at Home: Community Children's Nursing Services (DOH, 2011).

Other benefits include raising the profile of the hospice world among statutory organisations and encouraging health and social care professionals to think differently about how children's hospice services might be accessed to better meet the needs of children and their families.

This is a two year pilot project. Success will be measured in terms of number of new referrals to the service as well as capturing those families that we have been able to 're engage' with the hospice via the new community service; those that are referred and accepted to the hospice, but have been too frightened to access. Feedback will also be obtained from children, young people and parents every six months.

\section{P-188 A PARTNERSHIP APPROACH TO END OF LIFE CARE DISCHARGES}

${ }^{1}$ Chloe Longmore, ${ }^{2}$ Jane Penny, ${ }^{3}$ Penny Jones. 'Marie Curie, London, UK; ${ }^{2}$ East Surrey Hospital; ${ }^{3}$ St Catherine's Hospice

\subsection{6/bmjspcare-2016-001245.210}

Getting patients from acute hospitals into the community at the end of life is difficult. The problems include:

- Patients and carers having a poor experience at the end of life

- Complaints to the acute trust

- Patients not achieving their preferred care setting or place of death

- Beds being blocked in the acute trust.

The problem is caused by:

1. The complexity of discharging a patient at the end of life

2. Lack of rapid access to care in the community.

Getting care right at the end of life is of paramount importance. There is only one chance to get it right and meeting preferred place of care can be very important to a patient and carers.

A pilot project between an acute trust, hospice and charity has been in operation since January 2015 and works in two ways:

- A new role was created in the trust, discharge liaison practitioners, to identify patients at the end of life and case manage their discharge to their preferred place of care

- The charity and hospice partners collaborated to provide a team of HCAs in the community rapidly available to support patients with short packages of care until statutory services are able to take over.

The project objectives include:

- Improving the experience of patients at the end-of-life

- Increasing the percentage of patients achieving their preferred place of care and death

- Reducing discharge delays at the end-of-life

- Saving bed days for the acute trust.

The project has supported over 500 patients and is currently being evaluated by the charity partner with results due in September 2016. The project partners will then determine the project future based on the learning from this evaluation. 